\title{
VIABILIDADE DA PRODUÇÃO DE PÃO, UTILIZANDO FARINHA MISTA DE TRIGO E MANDIOCA EM DIFERENTES PROPORÇÕES
}

\author{
RENATA ERNLUND DE FREITAS * \\ SÔNIA CACHOEIRA STERTZ * \\ NINA WASZCZYNSKYJ **
}

\begin{abstract}
Realizou-se teste de panificação para estudar a possibilidade de substituição da farinha de trigo por farinha de mandioca, em proporções que variaram de 10 a 40\%. Após a cocção, os pães foram submetidos à avaliação sensorial e os resultados analisados estatisticamente. Concluiu-se que os pães elaborados com 10 e $20 \%$ de farinha de mandioca em substituição à farinha de trigo resultaram em produtos com textura macia e boa aceitabilidade.
\end{abstract}

\section{INTRODUÇÃO}

Panificação é o termo genérico que exprime uma das mais primitivas práticas da tecnologia de alimentos, e que apesar de amplamente desenvolvida, guarda os princípios básicos de sua existência milenar (4).

Pelas médias históricas de produção de trigo, os estoques mundiais podem ser considerados baixos e com tendência decrescente. A produção nacional para 1997 deverá perfazer aproximadamente 2,6 milhões de toneladas, tornando-se $21,2 \%$ inferior à obtida em 1996. Tal produção representará apenas $32,5 \%$ do consumo interno de trigo, sendo que o restante da demanda deverá ser suprido pela importação, principalmente da Argentina (8).

Há muito tempo, os pães e as pastas têm sido feitos com farinhas de cereais, raízes, legumes e tubérculos. Antes mesmo do pão de trigo, já se produzia pães de milho na América do Sul, de sorgo na África, de centeio no nordeste e leste europeu e de mandioca em países tropicais (9).

Alunas do Curso de Pós-Graduação em Tecnologia Química, Concentração em Tecnologia de Alimentos, Universidade Federal do Paraná.

* Professora do Curso de Pós-Graduação em Tecnologia Química e do Departamento de Tecnologia Química, Universidade Federal do Paraná. 
As farinhas ditas não panificáveis são aquelas cuja massa não permite a extração do glúten e desta forma, os pães produzidos não apresentam qualidade idêntica aos pães de glúten. Para o aproveitamento destas farinhas é necessário misturá-las à farinha de trigo, com predominância desta última nas proporções da mistura. A adição, com manutenção das características iniciais do pão de farinha pura de trigo, é possível até $20 \%$, desde que sejam empregados aditivos e produtos enzímicos, assim como efetuados tratamentos prévios de ordem física nas farinhas não panificáveis (3).

A farinha de mandioca é uma farinha não panificável, rica em amido, que apresenta a particularidade de diminuir gradualmente o poder de absorção de água, à medida que se aumenta sua proporção na mistura com a farinha de trigo. Neste caso, no momento do cozimento da massa, deve-se aumentar a quantidade de água adicionada, quando as proporções de farinha mista forem superiores a $10 \%$, pois o amido presente nestas farinhas absorverá água durante a gelatinização.

De acordo com CIACCO \& APPOLONIA (5) a substituição de parte da farinha de trigo por farinha de tubérculos, nos produtos de panificação, é possível nos níveis de 5 a 15\%, sem afetar a qualidade do produto final, sendo que pães produzidos com $10 \%$ de farinha de mandioca apresentam boa aceitabilidade.

As farinhas mistas são constituídas principalmente por produtos locais e devem combinar alto valor nutritivo com boas características de processamento. Sob o ponto de vista da qualidade, seus produtos devem ser comparáveis aos similares de trigo. O uso de farinhas mistas pode proporcionar melhoria da qualidade nutricional dos alimentos consumidos pela população, em função da escolha de seus componentes e proporções, além de servir como estímulo à agricultura e à indústria local (3).

O Estado do Paraná é atualmente o maior produtor nacional de mandioca, cuja estimativa de produção para 1996/97 é de 3,2 milhões de toneladas. O Estado conta com aproximadamente 207 indústrias farinheiras e 30 fecularias, algumas com capacidade de processar até 400 t/dia de raízes, concentradas principalmente na região noroeste (8).

No mundo, a mandioca é destinada principalmente ao consumo humano, sendo que em cerca de 14 países é o alimento predominante na dieta de 700 milhões de pessoas. No Brasil, constitui-se em hábito alimentar, particularmente nas regiões Norte e Nordeste (6).

A fabricação de pães de farinha mista, principalmente de feijão, batata e cevada, foi bastante difundida nos períodos pós-guerra, devido à 
deficiência na produção de trigo e a necessidade de se atender a demanda da população. Os governos vem dando maior atenção à pesquisa de pães de farinha mista, no sentido de seu melhoramento tecnológico e nutricional, para estarem preparados para o suprimento de pão em melhores condições que no pós-guerra. Motivos não faltam na época atual, para tal preocupação haja visto o crescimento da população em progressão geométrica e o consumo diário do pão pela maior parte desta. A população brasileira está familiarizada com pão branco de qualidade, sem interferência das farinhas mistas, sendo notórias tais contradições, em um país que ainda não é auto-suficiente quanto à produção de trigo $(3,9)$.

O presente trabalho teve como objetivo a elaboração de pães de farinha mista, com substituição de parte da farinha de trigo por farinha de mandioca, nas proporções de 0, 10, 20, 30 e 40\%, e posterior avaliação sensorial.

\section{MATERIAL E MÉTODOS}

\subsection{MATERIAL}

Os pães foram elaborados com farinha de trigo especial (ANACONDA) e farinha de mandioca branca, adquiridas no comércio local. Esta última foi moída em moinho de disco (ALPHA), a fim de apresentar granulometria semelhante à da farinha de trigo. A massa dos pães foi preparada com auxílio de máquina para fabricação de pães WELBIT modelo ABM -100-4.

\subsection{MÉTODOS}

Nas amostras formuladas considerou-se como padrão, pães com 100\% de farinha de trigo. As demais variaram em proporções de 10, 20, 30 e $40 \%$ de farinha de mandioca em relação à quantidade de farinha mista total.

Produziu-se os pães de acordo com a formulação básica recomendada pelo fabricante da máquina para elaboração de pão WELBILT, com algumas alterações no teor de água e sal, a fim de adequar a formulação ao propósito do trabalho (Tabela 1 ). 
TABELA 1 - FORMULAÇÃO UTILIZADA PARA A ELABORAÇÃO DOS PÃES

\begin{tabular}{lccccc}
\hline Ingredientes (\%) & \multicolumn{5}{c}{ Amostras } \\
\hline & Padrão & $\mathbf{1 0 \%}$ & $\mathbf{2 0 \%}$ & $\mathbf{3 0 \%}$ & $\mathbf{4 0 \%}$ \\
\hline - Farinha de trigo & 100,00 & 90,00 & 80,00 & 70,00 & 60,00 \\
- Farinha de mandioca & - & 10,00 & 20,00 & 30,00 & 40,00 \\
- Água & 60,00 & 60,00 & 60,00 & 65,25 & 82,75 \\
- Fermento biológico & 2,75 & 2,75 & 2,75 & 2,75 & 2,75 \\
- Sal & 2,75 & 2,75 & 2,75 & 2,75 & 2,75 \\
- Gordura vegetal hidrogenada & 5,00 & 5,00 & 5,00 & 5,00 & 5,00 \\
- Açúcar & 4,55 & 4,25 & 4,25 & 4,25 & 4,25 \\
- Leite em pó desnatado & 3,00 & 3,00 & 3,00 & 3,00 & 3,00 \\
\hline
\end{tabular}

A composição básica das farinhas de trigo especial e de mandioca estão apresentadas na Tabela 2.

TABELA 2 - COMPOSIÇÃO BÁSICA DAS FARINHAS UTILIZADAS

\begin{tabular}{lcc}
\hline Componente (\%) & Farinha de trigo & Farinha de mandioca \\
\hline Umidade & 13,73 & 9,1 \\
Proteínas & 10,00 & 1,1 \\
Lipídios & 0,28 & 0,5 \\
Fibras & 0,32 & 2,2 \\
Cinzas & 1,38 & 1,1 \\
Carboidratos & 74,2 & 88,2 \\
Valor calórico (Kcal/100g) & 339,68 & 363 \\
\hline
\end{tabular}

Os pães foram elaborados pelo método direto, conforme apresentado na Figura 1.

Foram realizadas determinações de volume, volume específico e peso dos pães elaborados, 12 horas após a cocção dos mesmos. O volume dos pães foi determinado pelo deslocamento de um volume conhecido de sementes de colza em recipiente apropriado e o volume específico obtido pela razão entre o volume e o peso final dos pães (7). 
A avaliação sensorial dos pães foi realizada utilizando-se escala hedônica estruturada de 5 pontos, provadores semi-treinados e amostras codificadas aleatoriamente com três dígitos. Os dados obtidos na avaliação sensorial foram analisados estatisticamente através da aplicação de análise de variância e teste de Tukey para comparação de médias $(1,2)$.

FIGURA 1 - FLUXOGRAMA BÁSICO DO MÉTODO EMPREGADO PARA A ELABORAÇÃO DOS PÃES

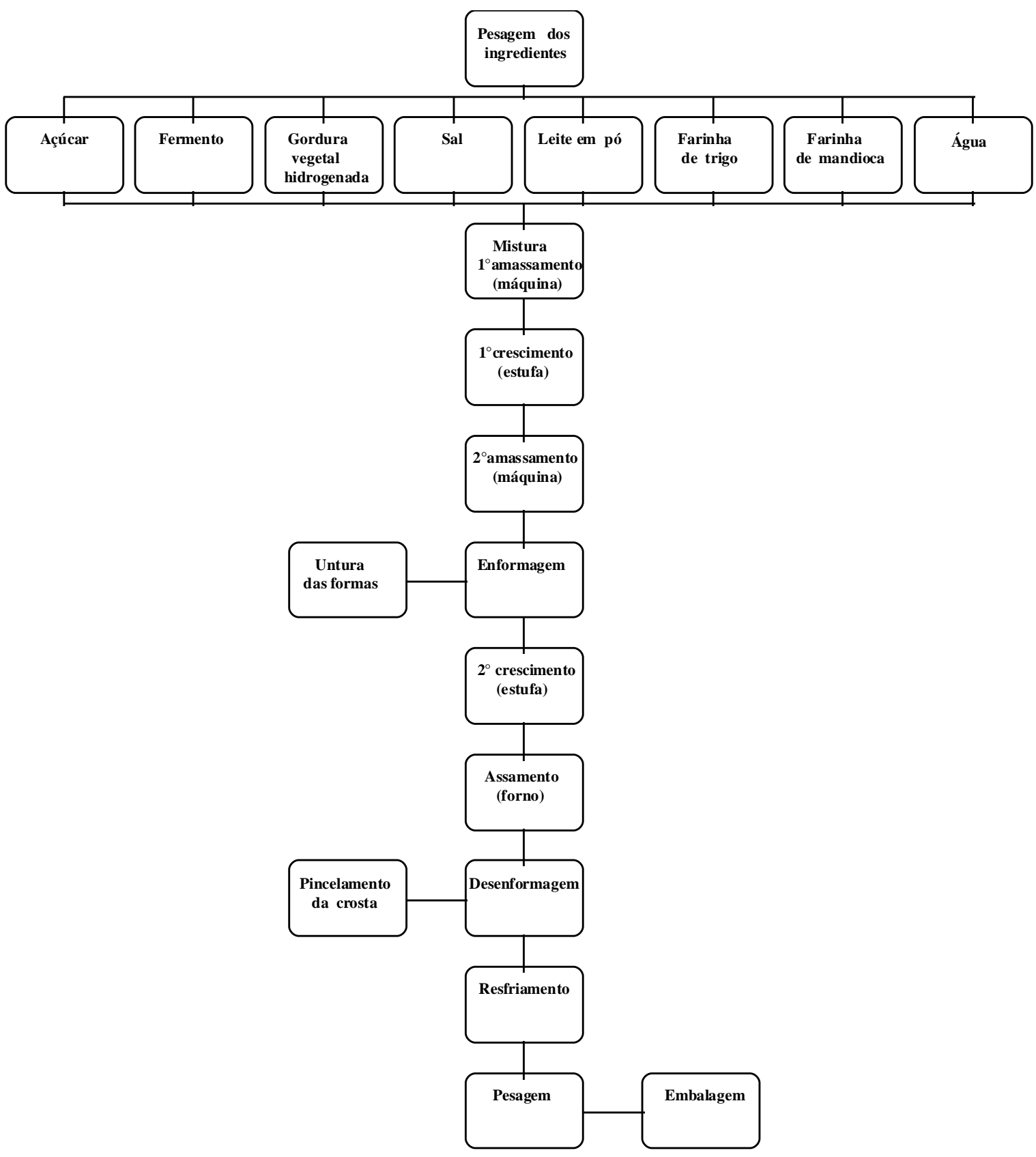


De acordo com a Tabela 3 pode-se observar que, o volume específico obtido pelo padrão $(3,25)$ apresentou valor pouco superior aos obtidos pelas amostras com $10 \%$ e $20 \%$ de farinha de mandioca $(3,20$ e 2,90, respectivamente). Apesar desta diferença, os pães elaborados com 10 e $20 \%$ de farinha de mandioca mostraram-se macios e de boa aceitabilidade. A partir da adição de $30 \%$ de farinha de mandioca à farinha total ocorreu aumento no peso dos pães e nas perdas na cocção, além de diminuição do volume específico, tendo como resultado pães de miolo mais compacto e menor aceitabilidade.

\section{TABELA 3 - RESULTADOS OBTIDOS PARA AS DETERMINAÇÕES REALIZADAS NOS PÃES}

\begin{tabular}{lccccc}
\hline Determinação & \multicolumn{5}{c}{ Amostras } \\
\hline & Padrão & $\mathbf{1 0 \%}$ & $\mathbf{2 0 \%}$ & $\mathbf{3 0 \%}$ & $\mathbf{4 0 \%}$ \\
Peso final (g) & 314 & 311 & 303 & 315 & 318 \\
Volume específico (mL/g) & 3,25 & 3,20 & 2,90 & 2,52 & 2,51 \\
Perdas na cocção (g) & 26 & 27 & 22 & 35 & 65 \\
\hline
\end{tabular}

As características visuais dos pães elaborados estão apresentadas na Figura 2. FIGURA 2 - CARACTERÍSTICAS VISUAIS INTERNAS E EXTERNAS
DOS DIFERENTES PÃES ELABORADOS 
Os resultados obtidos na avaliação sensorial dos pães estão apresentados na Tabela 4.

TABELA 4 - CARACTERÍSTICAS SENSORIAIS DOS PÃES AVALIADOS

\begin{tabular}{lccccc}
\hline Características externas * $^{*}$ & \multicolumn{5}{c}{ Amostras } \\
\cline { 2 - 6 } & Padrão & $\mathbf{1 0 \%}$ & $\mathbf{2 0 \%}$ & $\mathbf{3 0 \%}$ & $\mathbf{4 0 \%}$ \\
\hline Simetria & $4,9^{\mathrm{a}}$ & $4,6^{\mathrm{a}}$ & $4,4^{\mathrm{a}}$ & $4,5^{\mathrm{a}}$ & $2,7^{\mathrm{b}}$ \\
Cor da crosta** & $4,5^{\mathrm{a}}$ & $4,3^{\mathrm{ab}}$ & $4,3^{\mathrm{ab}}$ & $4,2^{\mathrm{ab}}$ & $2,9^{\mathrm{b}}$ \\
Textura da crosta & $4,9^{\mathrm{a}}$ & $4,2^{\mathrm{bc}}$ & $4,4^{\mathrm{ab}}$ & $3,9^{\mathrm{bc}}$ & $3,6^{\mathrm{c}}$ \\
Forma & $4,9^{\mathrm{a}}$ & $4,4^{\mathrm{a}}$ & $4,0^{\mathrm{a}}$ & $4,1^{\mathrm{a}}$ & $2,3^{\mathrm{b}}$
\end{tabular}

Características internas

Tamanho das células

$\begin{array}{lllll}4,6^{\mathrm{a}} & 4,0^{\mathrm{a}} & 4,7^{\mathrm{a}} & 4,2^{\mathrm{a}} & 2,6^{\mathrm{b}} \\ 4,3^{\mathrm{a}} & 3,7^{\mathrm{ab}} & 4,5^{\mathrm{a}} & 3,9^{\mathrm{ab}} & 2,4^{\mathrm{b}} \\ 4,9^{\mathrm{a}} & 4,6^{\mathrm{a}} & 4,4^{\mathrm{a}} & 3,5^{\mathrm{b}} & 2,7^{\mathrm{b}} \\ 4,9^{\mathrm{a}} & 4,5^{\mathrm{ab}} & 4,4^{\mathrm{ab}} & 3,9^{\mathrm{b}} & 3,1^{\mathrm{c}} \\ 4,7^{\mathrm{a}} & 4,6^{\mathrm{a}} & 4,6^{\mathrm{a}} & 4,4^{\mathrm{ab}} & 3,5^{\mathrm{b}} \\ 4,3^{\mathrm{ab}} & 4,5^{\mathrm{a}} & 4,5^{\mathrm{a}} & 4,5^{\mathrm{a}} & 3,3^{\mathrm{b}}\end{array}$

Distribuição das células**

Textura

Cor do miolo

Sabor

$4,3^{\mathrm{ab}}$

$4,5^{\mathrm{a}}$

, $3^{\mathrm{b}}$

* Médias seguidas pela mesma letra, na mesma linha não diferem estatisticamente pelo teste de Tukey ao nível de $1 \%$ de probabilidade.

** Médias seguidas pela mesma letra, na mesma linha não diferem estatisticamente pelo teste de Tukey ao nível de $5 \%$ de probabilidade.

Os pães elaborados com até $30 \%$ de farinha de mandioca não apresentaram diferença estatisticamente significativa em relação ao padrão para as características de simetria, forma, tamanho e distribuição das células, sabor e aroma, sendo bem aceitos pelos provadores. Já os produzidos com $40 \%$ de farinha de mandioca apresentaram médias bem abaixo das obtidas para os demais pães.

À medida em que se aumentou a proporção de farinha de mandioca (acima de 30\%) na farinha de mista observou-se deficiência no crescimento do pão, diminuição do volume, aumento dos espaços intercelulares, textura mais pobre, miolo mais escuro, sabor e aroma mais pronunciados, características não apreciadas pelos provadores.

As maiores médias obtidas pelos pães elaborados com farinha de mandioca foram para as características de sabor e aroma. Para esta última, a amostra com $20 \%$ de farinha de mandioca superou o padrão, devido ao sabor e aroma agradáveis da farinha de mandioca. 
O pão elaborado com $20 \%$ de farinha de mandioca mostrou-se superior ao produzido com $10 \%$ para as características de textura da crosta, tamanho e distribuição das células, obtendo excelentes médias $(4,4,4,7$ e 4,5, respectivamente).

Os pães elaborados com 10 e $20 \%$ de farinha de mandioca não apresentaram diferença significativa na análise estatística em relação ao padrão para as características analisadas, com exceção da textura da crosta (média de 4,2 para a amostra com 10\% de farinha de mandioca). Por sua vez, para as características de tamanho e distribuição das células, a amostra com $20 \%$ de farinha de mandioca apresentou médias superiores às do padrão.

O pão elaborado com $20 \%$ de farinha de mandioca foi considerado ideal, superando o padrão em algumas características na preferência de $60 \%$ dos provadores (Figura 3).

FIGURA 3 - PERFIL DE CARACTERÍSTICAS INTERNAS E EXTERNAS DOS PÃES ANALISADOS

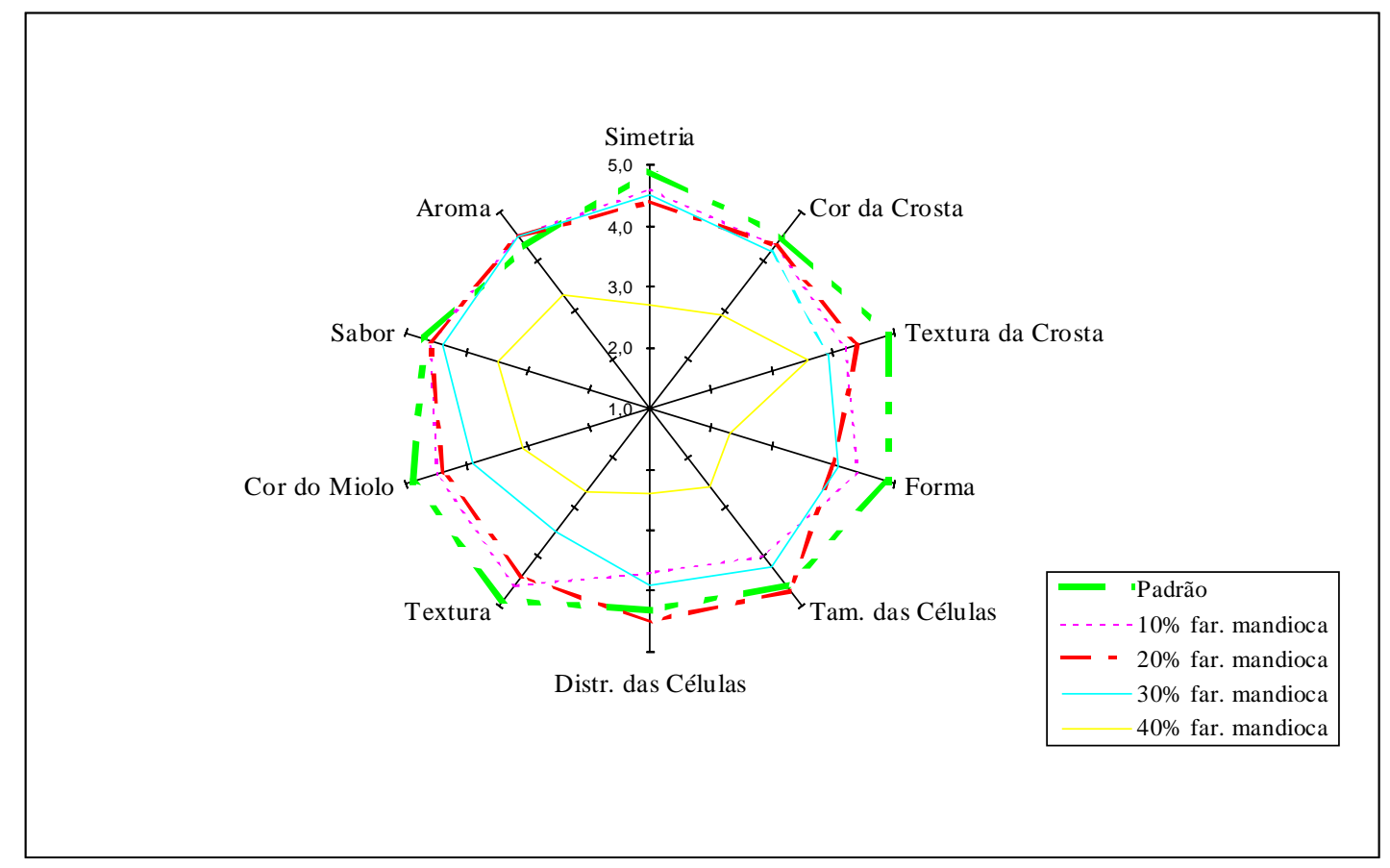


A avaliação sensorial e estatística dos pães elaborados mostrou que os pães produzidos com $20 \%$ de farinha de mandioca foram os mais aceitos, superando até mesmo o padrão na preferência de $60 \%$ dos provadores.

A substituição de parte da farinha de trigo por farinha de mandioca em até $30 \%$ pode ser realizada sem grande alteração do produto final.

Para maior aceitabilidade dos pães com adição de 30\% de farinha de mandioca recomenda-se experimentos posteriores, utilizando técnicas como o pré-tratamento farinha ou uso de aditivos, que podem proporcionar à farinha de mandioca características de textura e sustentação semelhantes às da farinha de trigo.

\section{Abstract}

Breadmaking tests were conduced to evaluate the possibility of wheat flour substitution by cassava flour in proportions ranging from 10 to $40 \%$. After baking, all breads were sensorially evaluated and the results were statistically analised. Breads produced with 10 to $20 \%$ of cassava flour in substitution of wheat flour resulted on soft texture and well aceptable products.

ANEXO 1 - VALORES OBTIDOS NA ANÁLISE DE VARIÂNCIA DAS CARACTERÍSTICAS DOS PÃES ELABORADOS

\section{CARACTERÍSTICAS EXTERNAS}

\section{Simetria}

\begin{tabular}{lcccc}
\hline $\begin{array}{c}\text { Fonte de } \\
\text { variação }\end{array}$ & $\begin{array}{c}\text { Graus de } \\
\text { liberdade }\end{array}$ & $\begin{array}{c}\text { Soma dos } \\
\text { Quadrados }\end{array}$ & $\begin{array}{c}\text { Quadrados } \\
\text { médios }\end{array}$ & F calculado \\
\hline Amostra & 4 & 25,91 & 6,48 & $17,05^{*}$ \\
Provador & 8 & 4,8 & 0,6 & $1,57^{\text {ns }}$ \\
Resíduo & 32 & 12,4 & 0,38 & \\
Total & 44 & 42,8 & & \\
ns - Não significativo. & & & \\
Significativo a 1\% de probabilidade. & &
\end{tabular}




\section{Cor da crosta}

\begin{tabular}{ccccc}
\hline $\begin{array}{c}\text { Fonte de } \\
\text { variação }\end{array}$ & $\begin{array}{c}\text { Graus de } \\
\text { liberdade }\end{array}$ & $\begin{array}{c}\text { Soma dos } \\
\text { Quadrados }\end{array}$ & $\begin{array}{c}\text { Quadrados } \\
\text { médios }\end{array}$ & F calculado \\
\hline Amostra & 4 & 16,13 & 4,03 & $3,33^{*}$ \\
Provador & 8 & 8,0 & 1 & $0,83^{\text {ns }}$ \\
Resíduo & 32 & 38,67 & 1,21 & \\
Total & 44 & 62,8 & & \\
\hline
\end{tabular}

ns - Não significativo.

* Significativo a $5 \%$ de probabilidade.

\section{Textura da crosta}

\begin{tabular}{ccccc}
\hline $\begin{array}{c}\text { Fonte de } \\
\text { variação }\end{array}$ & $\begin{array}{c}\text { Graus de } \\
\text { liberdade }\end{array}$ & $\begin{array}{c}\text { Soma dos } \\
\text { Quadrados }\end{array}$ & $\begin{array}{c}\text { Quadrados } \\
\text { médios }\end{array}$ & F calculado \\
\hline Amostra & 4 & 8,22 & 2,055 & $12,843^{*}$ \\
Provador & 8 & 15,58 & 1,95 & $12,187^{*}$ \\
Resíduo & 32 & 4,98 & 0,16 & \\
Total & 44 & 28,78 & & \\
\hline
\end{tabular}

* Significativo a 1\% de probabilidade.

\section{Forma}

\begin{tabular}{ccccc}
\hline $\begin{array}{c}\text { Fonte de } \\
\text { variação }\end{array}$ & $\begin{array}{c}\text { Graus de } \\
\text { liberdade }\end{array}$ & $\begin{array}{c}\text { Soma dos } \\
\text { Quadrados }\end{array}$ & $\begin{array}{c}\text { Quadrados } \\
\text { médios }\end{array}$ & F calculado \\
\hline Amostra & 4 & 33,91 & 8,48 & $18,84^{*}$ \\
Provador & 8 & 8,71 & 1,09 & $2,42^{\text {ns }}$ \\
Resíduo & 32 & 14,29 & 0,45 & \\
Total & 44 & 56,91 & & \\
\hline
\end{tabular}

ns - Não significativo.

* Significativo a $1 \%$ de probabilidade.

\section{CARACTERÍSTICAS EXTERNAS}

\section{Tamanho das células}

\begin{tabular}{ccccc}
\hline $\begin{array}{c}\text { Fonte de } \\
\text { variação }\end{array}$ & $\begin{array}{c}\text { Graus de } \\
\text { liberdade }\end{array}$ & $\begin{array}{c}\text { Soma dos } \\
\text { Quadrados }\end{array}$ & $\begin{array}{c}\text { Quadrados } \\
\text { médios }\end{array}$ & F calculado \\
\hline Amostra & 4 & 25,69 & 6,42 & $19,45^{*}$ \\
Provador & 8 & 6,41 & 0,8 & $2,42^{\text {ns }}$ \\
Resíduo & 32 & 10,71 & 0,33 & \\
Total & 44 & 42,8 & & \\
\hline ns - Não significativo. & & & \\
* Significativo a 1\% de probabilidade. &
\end{tabular}




\section{Distribuição das células}

\begin{tabular}{ccccc}
\hline $\begin{array}{c}\text { Fonte de } \\
\text { variação }\end{array}$ & $\begin{array}{c}\text { Graus de } \\
\text { liberdade }\end{array}$ & $\begin{array}{c}\text { Soma dos } \\
\text { Quadrados }\end{array}$ & $\begin{array}{c}\text { Quadrados } \\
\text { médios }\end{array}$ & F calculado \\
\hline Amostra & 4 & 24,31 & 6,08 & $3,40^{*}$ \\
Provador & 8 & 17,6 & 2,2 & $1,23^{\mathrm{ns}}$ \\
Resíduo & 32 & 57,29 & 1,79 & \\
Total & 44 & 99,2 & & \\
\hline
\end{tabular}

ns - Não significativo.

* Significativo a 5\% de probabilidade.

\section{Textura}

\begin{tabular}{ccccc}
\hline $\begin{array}{c}\text { Fonte de } \\
\text { variação }\end{array}$ & $\begin{array}{c}\text { Graus de } \\
\text { liberdade }\end{array}$ & $\begin{array}{c}\text { Soma dos } \\
\text { Quadrados }\end{array}$ & $\begin{array}{c}\text { Quadrados } \\
\text { médios }\end{array}$ & F calculado \\
\hline Amostra & 4 & 27,91 & 6,98 & $27,92^{*}$ \\
Provador & 8 & 4,8 & 0,6 & $2,4^{\text {ns }}$ \\
Resíduo & 32 & 8,09 & 0,25 & \\
Total & 44 & 40,8 & & \\
\hline
\end{tabular}

ns - Não significativo.

* Significativo a $1 \%$ de probabilidade.

\section{Cor do miolo}

\begin{tabular}{ccccc}
\hline Fonte de & $\begin{array}{c}\text { Graus de } \\
\text { liberdade }\end{array}$ & $\begin{array}{c}\text { Soma dos } \\
\text { Quadrados }\end{array}$ & $\begin{array}{c}\text { Quadrados } \\
\text { médios }\end{array}$ & F calculado \\
\hline Amostra & 4 & 17,47 & 4,37 & $25,71^{*}$ \\
Provador & 8 & 3,78 & 0,47 & $2,76^{\text {ns }}$ \\
Resíduo & 32 & 5,33 & 0,17 & \\
Total & 44 & 26,58 & & \\
\hline
\end{tabular}

ns - Não significativo.

* Significativo a $1 \%$ de probabilidade.

\section{Sabor}

\begin{tabular}{ccccc}
\hline $\begin{array}{c}\text { Fonte de } \\
\text { variação }\end{array}$ & $\begin{array}{c}\text { Graus de } \\
\text { liberdade }\end{array}$ & $\begin{array}{c}\text { Soma dos } \\
\text { Quadrados }\end{array}$ & $\begin{array}{c}\text { Quadrados } \\
\text { médios }\end{array}$ & F calculado \\
\hline Amostra & 4 & 8,98 & 2,245 & $6,60^{*}$ \\
Provador & 8 & 8,98 & 1,12 & $3,29 *$ \\
Resíduo & 32 & 11,02 & 0,34 & \\
Total & 44 & 28,98 & & \\
\hline
\end{tabular}

ns - Não significativo.

* Significativo a $1 \%$ de probabilidade. 


\section{Aroma}

\begin{tabular}{ccccc}
\hline $\begin{array}{c}\text { Fonte de } \\
\text { variação }\end{array}$ & $\begin{array}{c}\text { Graus de } \\
\text { liberdade }\end{array}$ & $\begin{array}{c}\text { Soma dos } \\
\text { Quadrados }\end{array}$ & $\begin{array}{c}\text { Quadrados } \\
\text { médios }\end{array}$ & F calculado \\
\hline Amostra & 4 & 10,13 & 2,53 & $5,62^{*}$ \\
Provador & 8 & 16 & 2 & $4,44^{*}$ \\
Resíduo & 32 & 14,67 & 0,45 & \\
Total & 44 & 40,8 & & \\
\hline
\end{tabular}

ns - Não significativo.

* Significativo a $1 \%$ de probabilidade.

\section{REFERÊNCIAS BIBLIOGRÁFICAS}

1 ASSOCIAÇÃO BRASILEIRA DE NORMAS TÉCNICAS. Análise sensorial: PN 13:014.01-015. São Paulo, 1994.

2 ASSOCIAÇÃO BRASILEIRA DE NORMAS TÉCNICAS. Métodos de análise sensorial dos alimentos e bebidas: terminologia. NBR 12994. Rio de Janeiro, 1993. 2 p.

3 BAR, W. H., PIZZINATTO, A. Análise e avaliação de trigo e de suas farinhas quanto às qualidades tecnológicas. Campinas : ITAL, 1979. [120] $p$.

4 BUCIONE JR., A.R. Pão tipo francês: tecnologia de processamento e principais matérias-primas usadas no fabrico. B. SBCTA, Campinas, p. 235-246, 1979.

5 CIACCO, C. T., D'APPOLONIA, B. L. Baking studies with cassava and yam flour. II. Rheological and baking studies of tuber wheat flour blends. Cereal Chemistry, v. 55, n. 4, p. 423-435, 1978.

6 CONCEIÇÃO, A. J. A mandioca. 2. ed. São Paulo : Nobel, 1981. $382 \mathrm{p}$.

7 EL-DASH, A., MAZZARI, M. R., GERMANI, R. Tecnologia de farinhas mistas: uso de farinha mista de trigo e mandioca na produção de pães. EMBRAPA/SPIPP, Brasília, v. 6, p. 20-22, 1994.

8 PARANÁ. Secretaria de Estado da Agricultura e do Abastecimento do Paraná. Acompanhamento da situação agropecuária do Paraná. DERAL, Curitiba, v. 23, n. 4, abr. 1997. 91 p.

9 RUITER, D. de. Composite flours. Advances in Cereal Science and Technology, v. 2, p. 349-395, 1978. 